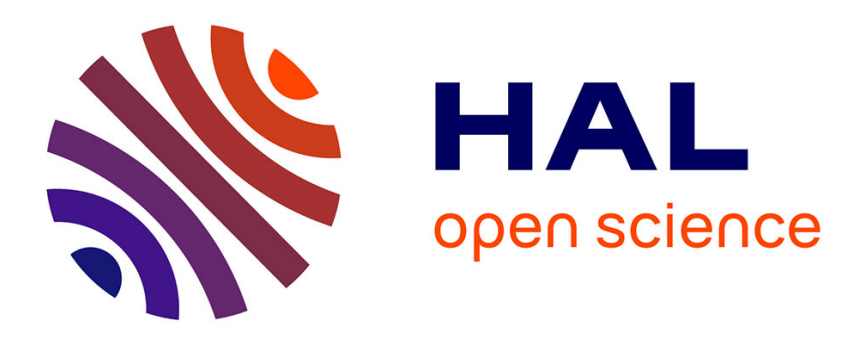

\title{
Electron nuclear double resonance (ENDOR) spectroscopy of the EL2 defect in GaAs
}

B.K. Meyer

\section{To cite this version:}

B.K. Meyer. Electron nuclear double resonance (ENDOR) spectroscopy of the EL2 defect in GaAs. Revue de Physique Appliquée, 1988, 23 (5), pp.809-816. 10.1051/rphysap:01988002305080900 . jpa00245885

\section{HAL Id: jpa-00245885 https://hal.science/jpa-00245885}

Submitted on 1 Jan 1988

HAL is a multi-disciplinary open access archive for the deposit and dissemination of scientific research documents, whether they are published or not. The documents may come from teaching and research institutions in France or abroad, or from public or private research centers.
L'archive ouverte pluridisciplinaire HAL, est destinée au dépôt et à la diffusion de documents scientifiques de niveau recherche, publiés ou non, émanant des établissements d'enseignement et de recherche français ou étrangers, des laboratoires publics ou privés. 


\title{
Electron nuclear double resonance (ENDOR) spectroscopy of the EL2 defect in GaAs
}

\author{
B. K. Meyer \\ Universität Paderborn, Fachbereich Physik, Warburger Str. 100 A, D-4790 Paderborn, F.R.G.
}

(Reçu le 18 août 1987, accepté le 12 février 1988)

\begin{abstract}
Résumé. - L'étude du défaut EL2 dans GaAs semi-isolant par spectroscopie ENDOR détectée optiquement (ODENDOR) montre que ce défaut est dû à une paire d'antisite arsenic-interstitiel arsenic, $\mathrm{As}_{\mathrm{Ga}}-\mathrm{As}_{\mathrm{i}}$. Les paramètres d'interaction hyperfine ainsi que la symétrie des premiers et deuxièmes voisins et de l'interstitiel ont été analysés. L'interprétation quantitative de l'interaction quadrupolaire permet de déduire le site et l'état de charge de l'interstitiel d'arsenic.
\end{abstract}

\begin{abstract}
Optically detected electron nuclear double resonance (ODENDOR) experiments in semiinsulating GaAs show that the As-antisite ESR spectrum is due to an arsenic antisite-As interstitial pair. The interaction parameters and symmetry of the nearest and next nearest As-ligands and of the single interstitial As atom were analysed. From a quantitative interpretation of the quadrupole interaction parameters the place and charge state of the interstitial As can be inferred.
\end{abstract}

\section{Introduction.}

The mid-gap level EL2 in GaAs is due to a defect of yet unknown microscopic structure, which has unique and fascinating properties. At low temperature it can be photoexcited into a metastable state which is responsible for the observed persistent quenching of the photocapacitance. It returns to the ground state only after thermal activation at $140 \mathrm{~K}$ [1]. Electron Spin Resonance (ESR) investigations of crystals grown under different melt stoichiometry conditions show that EL2 is related to an anion antisite $\mathrm{As}_{\mathrm{Ga}}$ ESR signal [2, 3]. Therefore, many defect models exist involving an anion antisite defect, isolated or complexed with vacancies or an interstitial [4-7].

The identification of EL2 with an $\mathrm{As}_{\mathrm{Ga}}-\mathrm{As}_{\mathrm{i}}$ complex in [7] was based on a combination of ESR and DLTS in electron irradiated $n$-type GaAs. In ESR, however, only the hyperfine interaction with the central nucleus is resolved, whereas the hyperfine interactions and symmetry of the ligands cannot be deduced from the ESR spectrum. Therefore, the identification of EL2 in reference [7] was a very indirect one : the role of the $A s_{i}$ and the assignment of its charge state and position were based on theoretical predictions and a comparison of diffusion data.

\section{The arsenic antisite and EL2.}

The correlation of the midgap donor EL2 $\left(\mathrm{EL}^{0}\right)$ with an arsenic antisite defect $\mathrm{As}_{\mathrm{Ga}}\left(\mathrm{EL}^{+}\right)$is based on the stoichiometry dependence of the EL2 formation [5]. Antisite defects detected by ESR in asgrown GaAs are in comparable concentration to EL2, also the thermal stability of EL2 and $\mathrm{As}_{\mathrm{Ga}}$ extends up to $950{ }^{\circ} \mathrm{C}[8,9]$.

An enhancement of the ESR signal is observed for plastically deformed $\mathrm{GaAs}$ as well as for electron and neutron irradiated material. There are however two indications that those additionally created defects are not identical to those in as-grown s.i. GaAs : along with the lower thermal stability (annealing takes place at $450^{\circ} \mathrm{C}$ for plastically deformed $\mathrm{GaAs}$ and at around $550^{\circ} \mathrm{C}$ for irradiated material) also the spin lattice relaxation time is shortened by orders of magnitude. No saturation of the ESR signal is observed in this damaged material [10,11]. In contrast saturation of the antisite ESR spectrum in as grown GaAs is observed in optically detected ESR experiments and in conventional ESR studies presented just recently $[12,13]$. It is suggested that both techniques detect the same $\mathrm{As}_{\mathrm{Ga}}$ species. The identification of EL2 with an isolated As antisite can however not be inferred from the ESR spectrum. The isotropic ESR spectrum (see Fig. 1) only resol- 


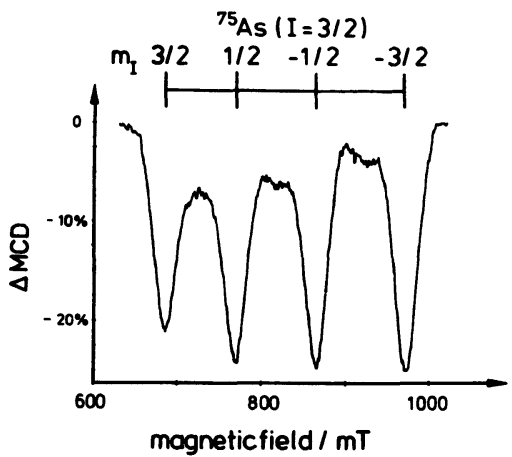

Fig. 1. - Optically detected electron spin resonance spectrum of the $\mathrm{EL}^{+}$defect in semi-insulating $\mathrm{GaAs}$ $(T=1.4 \mathrm{~K}, v=24.31 \mathrm{GHz})$.

ves the interaction of the paramagnetic electron with the central As nucleus $(I=3 / 2)$ on a gallium site (the quadruplet fingerprint spectrum). It is necessary to distinguish between the hypperfine (hf) interaction with the central nucleus and the ligand hyperfine interactions (lhf) with the nuclei of the defect environment. These interactions are the source of inhomogeneous broadening of the ESR lines resulting in the case of $\mathrm{As}_{\mathrm{Ga}}$ in $34 \mathrm{mT}$ broad ESR lines. In such a case it is not possible to decide from ESR measurements alone if the defect has perfect tetrahedral symmetry or if the defect is slightly distorted due to the presence of another nearby defect.

For the safe microscopic identification of the defect structure one has to resolve the ligand hf interactions and to determine their symmetry, which requires electron nuclear double resonance (ENDOR) experiments.

\section{Experimental realization.}

The optically detected ENDOR signals are measured as a radiofrequency ( $\mathrm{rf}$ ) induced change of the magnetic circular dichroism (MCD) under microwave resonance conditions $[14,15]$. Unlike in conventional ENDOR it was found that the ODENDOR effect is of the same order as the ODESR effect. This is apart from the sensitivity enhancement through the optical detection a great advantage for the analysis of the defect structure.

The measurements were made at $1.6 \mathrm{~K}$ with a computer controlled homodyne spectrometer. With an improved optical resonator the radio-frequency range was extended to $300 \mathrm{MHz}$.

The frequency positions of the ENDOR lines are determined by applying a particular peak search algorithm. Before this can be done digital filtering is usually applied. The digital filters conserve the first and second moments of the lines. Often deconvolution procedures are needed when too many ENDOR lines overlap [16].

We studied semi-insulating GaAs grown by the liquid encapsulated Czochralski technique, undoped, vanadium and chronium doped material giving the same results.

\section{Experimental results.}

The spin-Hamiltonion describing the defect, which has one unpaired electron, an isotropic $g$-factor as well as hf, lhf and quadrupole interactions (including the nuclear Zeeman-term) is [17] :

$$
\begin{aligned}
H=g \beta_{\mathrm{c}} & \mathbf{B}_{0} \mathbf{S}+\mathbf{S} \tilde{A}_{\mathrm{c}} \mathbf{I}_{\mathrm{c}}+ \\
& +\Sigma_{1}\left(\mathbf{S} \tilde{A}_{1} \mathbf{I}_{1}-g_{\mathrm{I}} \beta_{\mathrm{n}} \mathbf{B}_{0} \mathbf{I}_{1}+\mathbf{I}_{1} \tilde{Q}_{1} \mathbf{I}_{1}\right)
\end{aligned}
$$

The sum runs over all nuclei interacting with the unpaired electron. The symbols have their usual meaning [17]. On the condition that the anisotropic lhf constant $b$ and the nuclear quadrupole constant $q$ are small compared to the isotropic lhf constant $a$ and the nuclear Larmor frequency, respectively, the ENDOR frequencies are given in perturbation theory of first order :

$$
\begin{aligned}
& v_{\mathrm{ENDOR}}^{ \pm}+1 / h\left(m_{\mathrm{s}} W_{\mathrm{lhf}} \mp g_{I} \beta_{\mathrm{n}} B_{0} \pm m_{q} W_{q}\right) \\
& \text { with } \quad \mathrm{W}_{\mathrm{lhf}}=a+b\left(3 \cos ^{2} \alpha-1\right) \\
& W_{q}=3 q\left(3 \cos ^{2} \gamma-1\right)
\end{aligned}
$$

and $\alpha$ and $\gamma$ are the polar angles of $B_{0}$ in the principal lhf and quadripole axis systems, respectively.

$m_{q}=1 / 2\left(m_{I}+m_{I}^{\prime}\right), m_{q}$ is the average of the two nuclear spin quantum numbers connected by the NMR transition.

Each interacting nucleus gives rise to 2 ENDOR frequencies in the absence of quadrupole interactions and to $2 \times 21$ lines with quadrupole interactions for $S=1 / 2$. In order to determine the orientations and principal values of the $\mathrm{lhf}$ and quadrupole tensors, the ENDOR spectra have to be measured as a function of the crystal orientation with respect to the static magnetic field $B_{0}$.

Figure 2 shows the angular dependence of the ODENDOR lines in GaAs : $\mathrm{V}$, rotating the crystal in a (110) plane from [110] $=0^{\circ}$ towards [001] with respect to the magnetic field $B_{0}$. The dots represent the ENDOR line positions, their size the line intensity. All lines are due to ${ }^{75}$ As. The analysis of the angular dependence was complicated by several factors. For a tetrahedrally coordinated As antisite a simple angular pattern due to 4 ligands with [111]symmetry would be expected, 2 lines for $B_{0} \|[110]$ and 1 line for $B_{0} \|[100]$ for each $m_{\mathrm{s}}$-state. A large quadrupole interaction (nuclear spin of ${ }^{75} \mathrm{As} I=3 / 2$ ) influences the pattern so much that it is not easily recognized [18]. For each orientation of $B_{0}$ in a (110) plane one would expect 18 ENDOR lines due to 4 nearest neighbors (n.n.) of which 2 remain equival- 


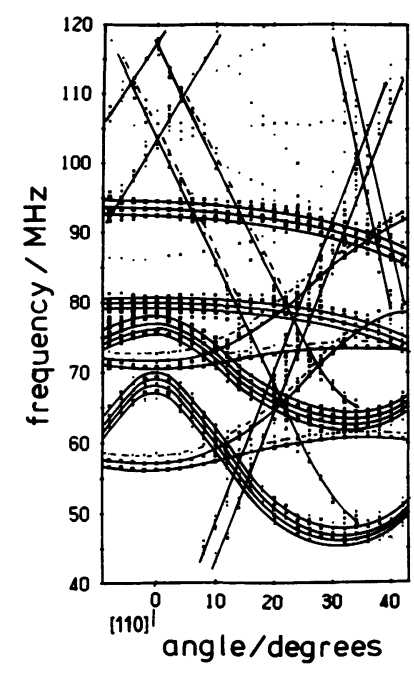

Fig. 2. - Angular dependence of the ODENDOR lines of $\mathrm{EL}^{+}$in semi-insulating $\mathrm{GaAs}: \mathrm{V}$ for rotation of the crystal in a (110)-plane from [110] $=0^{0}$ towards [001]. Solid lines and dashed drawn lines correspond to the four nearest As ligands, the dots above $80 \mathrm{MHz}$ to the additional As interstitial nucleus.

ent. But there are many more lines due to additional splittings (see e.g. around 80 and $95 \mathrm{Mhz}$ for $\left.B_{0} \|[110]\right)$, which arise from a large pseudo-dipolarcoupling of the nearest neighbors. The splittings are much larger than expected from current treatments of the effect [19], caused by a large anisotropic ligand hyperfine (lhf) interaction.

Compared to our earlier ODENDOR experiments on an GaAs : $\mathrm{Cr}$ sample the ENDOR lines were narrower by a factor of two. Also the improved experimental conditions allowed to extend the frequency range from about $90 \mathrm{MHz}$ to $300 \mathrm{MHz}$ with a better resolution in order to distinguish, whether a possible small distortion of the four nearest ligands or the pseudo-dipolar-coupling effects were responsible for the splittings in the ENDOR angular dependence. This improvement in experimental conditions and crystal material was decisive. Our earlier interpretation that two types of antisite defects, an isolated one and in addition a distorted defect are simultaneously present in s.i. as grown $\mathrm{GaAs}$ has to be revised [15]. The additional lines attributed previously to distorted defects are due to the ENDOR lines of the four nearest As ligands split by pseudodipolar couplings. Similar effects were observed in the ENDOR pattern of the neutral gallium vacancy in Gap [20].

The solid lines in figure 2 were calculated after diagonalising the spin-Hamiltonion (Eq. (1)) containing the central hf interactions and lhf and quadrupole interaction tensors for the [111] n.n. and the electron Zeeman term with the parameters given in table I. The interaction tensors are axially symmetric with respect to the [111]-axes within experimental accuracy.
Table I. - Hyperfine and ligand hyperfine interaction parameters of the EL2 ${ }^{+}\left(\mathrm{As}_{\mathrm{Ga}}-\mathrm{As}_{\mathrm{i}}\right)$ defect. $a$ : isotropic lhf, $b$ : anisotropic lhf parameters, $q:$ quadrupole interaction constant.

Interaction parameters

\begin{tabular}{|l|c|c|c|}
\cline { 2 - 4 } \multicolumn{1}{c|}{} & \multicolumn{1}{c|}{$a / \mathrm{MHz}$} & $b / \mathrm{MHz}$ & $q / \mathrm{MHz}$ \\
\hline $\begin{array}{l}\text { central } \\
\text { As }_{\mathrm{Ga}} \text { nucleus }\end{array}$ & $2656 \pm 15$ & & \\
\hline $\begin{array}{l}\text { ligand 1* } \\
\text { ligand 2-4 }\end{array}$ & 167.8 & $53.9 \pm 0.1$ & 12.2 \\
\hline inter- & $167.8 \pm 0.1$ & $53.9 \pm 0.1$ & $11.7 \pm 0.1$ \\
stitial As & $215 \pm 2$ & $44 \pm 1$ & $4.8 \pm 0.2$ \\
\hline As (IIIa) & $35.2 \pm 0.1$ & $-1.3 \pm 0.1$ & $2.8 \pm 0.1$ \\
As (IIIc) & $19.5 \pm 0.1$ & $3.2 \pm 0.1$ & $0.9 \pm 0.1$ \\
\hline
\end{tabular}

The interaction parameters for As nuclei IIIb could only be determined with less accuracy. They are very similar to those of shell IIIc.

* (From the experiment it is not posible to decide, whether ligand 1 has a slightly higher $q$ value compared to the ligands 2-4 or whether the isotropic interaction constant $a$ is slightly larger.)

There are, however, two types of additional lines : satellite lines, indicated by dashed lines in figure 2 , following the angular dependence of nearest neighbors (solid lines). They are not explainable by indirect coupling effects (See, however the discussion of the quadrupole interaction below) and ENDOR lines which do not follow the calculated angular dependence (see Fig. 2, the dots at frequencies above $80 \mathrm{MHz}$ ).

The full angular dependence of the additional lines above $80 \mathrm{MHz}$ could not be followed in this crystal orientation, because it is hidden under the other strong lines. By measuring the ENDOR spectra for $B_{0} \|$ [001] towards $B_{0} \|$ [11̄0] in a (110)-plane the variation of these lines in a frequency range from 100 to $140 \mathrm{MHz}$ could be followed. Their analysis yielded that they also belong to ${ }^{75} \mathrm{As}$ with [111]symmetry with interaction parameters given in table I.

The additional ENDOR lines can be measured across the whole MCD spectrum and in all four ESR lines and thus belong to the same defect. The intensity of the ENDOR lines is lower by a factor 4-8 compared to the lines of the nearest ligands which indicates the presence of one single nucleus. This result is supported by a simulation of the ESR linewidth $W_{1 / 2}$ taking into account the measured lhf interactions including those of 12 As-neighbors in the third neighbor shell, the ENDOR lines of which 
were measured in a frequency range between 10-30 $\mathrm{MHz}$ (see below). Including one additional [111] Asnucleus one obtains $W_{1 / 2 \text { exp. }}=32.5 \mathrm{mT}$ in excellent agreement with the experimental value of $W_{1 / 2 \text { calc. }}=33.5 \mathrm{mT}$, whereas without it one calculates only $26 \mathrm{mT}$. Assuming instead four [111] nuclei on lattice sites (e.g. 7th As-shell) it would be $42 \mathrm{mT}$, thus far too large (spin packet width taken from the ENDOR line width). Within the GaAs crystal structure one single [111] As ligand can only be an interstitial one along [111]. Therefore, the EL2 ${ }^{+}$ defect is a $\mathrm{As}_{\mathrm{Ga}}-\mathrm{As}_{\mathrm{i}}$ pair (Fig. 3) with $C_{3 v}$ symmetry. This symmetry is also clearly seen in the third shell III As ligands (12 nuclei). There are one subshell of 6 equivalent nuclei $\left(\mathrm{As}_{\mathrm{IIIc}}\right)$ and two subshells of three equivalent nuclei each $\left(\mathrm{As}_{\mathrm{III}}, \mathrm{As}_{\mathrm{III}}\right)$ (Fig. 3).



Fig. 3. - Model of the $\mathrm{As}_{\mathrm{Ga}}-\mathrm{As}_{\mathrm{i}}$ pair. The nearest As ligands are labelled 1 to 4 . The 12 next nearest neighbors are labelled III. Under the influence of the $\mathrm{As}_{\mathrm{i}}$ they split into three subshells, labelled IIIa, IIIb and IIIc. Hatched circles represent As, open circles $\mathrm{Ga}$ nuclei.

The ENDOR frequencies of the third shell neighbors are observed in the frequency range from 10 to $30 \mathrm{MHz}$ (Fig. 4). Lines with high intensity between 10 and $20 \mathrm{MHz}$ belong to the sub-shells $\mathrm{As}_{\mathrm{IIIb}, \mathrm{c}}$ and the less intense lines around $30 \mathrm{MHz}$ to the subshell $\mathrm{As}_{\mathrm{IIIa}}$. Figures $5 \mathrm{a}$ and $5 \mathrm{~b}$ show the angular dependence of these shells for rotating in a (110) plane from [110] $=0^{0}$ towards [001]. The less intense lines are marked by full circles, the drawn lines give the calculated angular dependence with the interaction parameters in table I. The analysis for the lines between 10 and $20 \mathrm{MHz}$ was more complicated due to many overlapping lines. Only the interactions of one subshell could clearly be analysed $\left(\mathrm{As}_{\text {IIIc }}\right.$, Fig. 5b). The ENDOR lines of subshell $\mathrm{As}_{\text {IIIb }}$ are in the same frequency range, the interaction parameters are only slightly different from shell

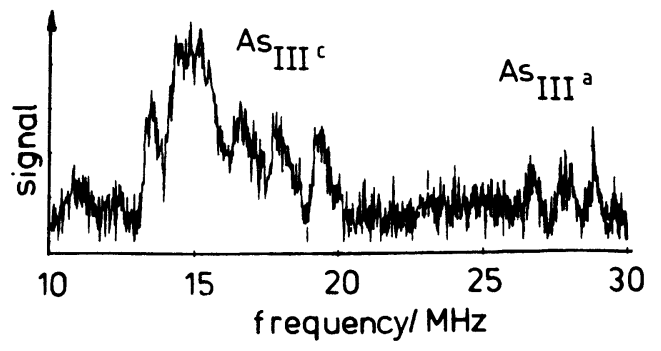

Fig. 4. - Optically detected ENDOR spectrum of the third shell As-ligands. The group of lines corresponding to subshells $\mathrm{As}_{\mathrm{IIIa}}$ and $\mathrm{As}_{\mathrm{III}, \mathrm{b}}$ are indicated.

a)

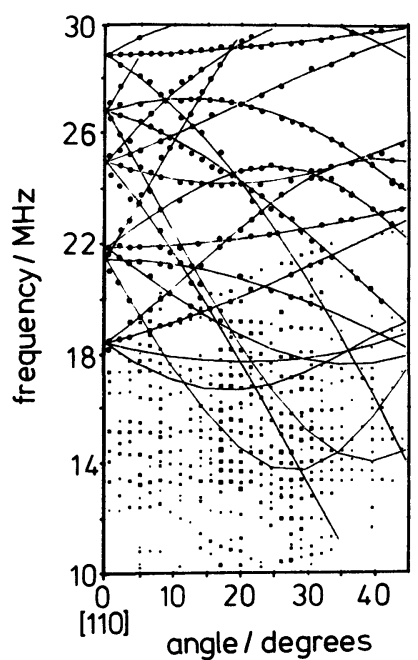

b)



Fig. 5. - Angular dependence of the ODENDOR lines of the third shell neighbours in semi-insulating GaAs : $\mathrm{V}$ for rotation in a (110)-plane from [110] $=0^{0}$ towards [001]. a) Full circles correspond to the interactions of the subshell $\mathrm{As}_{\text {IIIa }}$ (drawn lines : calculated angular dependence). b) Interactions of subshell $\mathrm{As}_{\text {IIIc }}$ (points : experimental data, drawn lines : calculated angular dependence).

$\mathrm{As}_{\text {IIIc }}$. No gallium interactions (second shell, 12 nuclei) could be detected. 


\section{Charge state and place of $\mathbf{A s}_{\mathbf{i}}$.}

The charge state of the interstitial must be such, that its resulting electron spin is zero (i.e. $\mathrm{As}^{+}, \mathrm{As}^{-}$, $\mathrm{As}^{+++}$). For a paramagnetic charge state, e.g. $\mathrm{As}_{\mathrm{i}}^{0}$, both constituents of the pair would be paramagnetic and could have either a fine structure dipole-dipole interaction (estimated to be approx. $50 \mathrm{mT}$ ) or due to exchange interaction be in a spin singulet or triplet state. This is not consistent with the observed ESR spectrum.

The site of $A s_{i}$ is determined by estimating the ligand quadrupole interaction constants, which have two major contributions (Fig. 6). One, $q(b)$, is due to the unpaired spin density in p-orbitals at the ligands measured by the anisotropic lhf interaction, $b,[21,22]$ and one, $q(p)$, due to the electric field gradient caused by the charge distribution including the Sternheimer antishielding effect. This interpretation of the quadrupole interaction constants gives very good agreement with the measured data for the transition metal impurities in III-V semiconductors (e.g. $\mathrm{V}^{3+}, \mathrm{Fe}^{3+}, \mathrm{Mn}^{2+}$ and $\mathrm{Ni}^{3+}$ [23]).

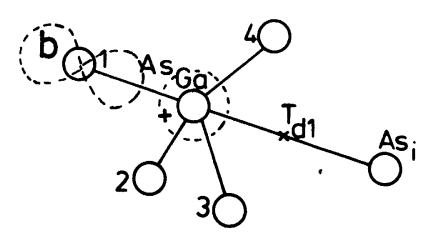

Fig. 6. - Model for the calculation of the quadrupole interaction constants.

The charge on the $\mathrm{As}_{\mathrm{Ga}}$, the $\mathrm{As}_{\mathrm{i}}$ and the ligands is estimated by analysing their hyperfine data using a linear combination of atomic orbitals approach [24].

The wavefunction of the defect $\Phi$ is approximated by

$$
\Phi=\Sigma_{\mathrm{i}} n_{\mathrm{i}} \Phi_{\mathrm{i}}
$$

$n_{\mathrm{i}}^{2}$ represents that part of $\Phi$ which is located at the neighbor i. At each As-site hybridization is taken into account

$$
\Phi_{\mathrm{i}}=\alpha_{\mathrm{i}} \Phi_{\mathrm{i}, \mathrm{s}}+\beta_{\mathrm{i}} \Phi_{\mathrm{i}, \mathrm{p}}
$$

with

$$
\alpha_{i}^{2}+\beta_{i}^{2}=1
$$

and $n_{\mathrm{i}}^{2}=N_{\mathrm{i}}\left(a_{\mathrm{i}} / a_{\mathrm{f}}+b_{\mathrm{i}} / b_{\mathrm{f}}\right)$ where $a_{\mathrm{f}}$ and $b_{\mathrm{f}}$ are the isotropic and anisotropic hf constants of the free As atom (4 s, $4 \mathrm{p})$ orbitals [25] and $N_{\mathrm{i}}$ is the number of nuclei in one shell.

When comparing the measured hf and lhf data (Tab. I) to the values of the free atom, we find that $18 \%$ of the unpaired electron resides on the central As on gallium site, $17 \%$ on each of the ligands 1-4 and $14 \%$ on the interstitial, while only $1 \%$ is on each of the 12 As neighbors in the third shell. On the ligands the main part of the spin density is localised in the p-orbitals, for the four nearest neighbors the values are $\alpha^{2}=0.078$ and $\beta^{2}=0.922$.

We used this spin density distribution also as a measure of the charge distribution. Treating the charges simply as point charges the two quadrupole contributions for the neighbors 1 and 2-4 are calculated. Within this picture the As on gallium site is not singly positively charged (in that case the electron should be located only at $\mathrm{As}_{\mathrm{Ga}}$ ). As the electron is spread over the ligands, the central As nucleus carries 1.82 positive charge, whereas, the ligands $1-4$ have 0.17 negative charge on each nucleus.

From the anisotropic lhf interaction $b=53.9 \mathrm{MHz}$ one calculates a $q(b)$ of $6.7 \mathrm{MHz}$, the point charge contribution on the nearest neighbors $(d=2.44 \AA)$ amounts $q(p)=6.3 \mathrm{MHz}$, in total $q=13 \mathrm{MHz}$. This estimated value is slightly larger than the experimental value $q=11.7 \mathrm{MHz}$. (A previous estimate of $q$ considered for the point charge contribution only one positive charge at the central As nucleus and thus resulted in smaller calculated values for $q$ [26].)

For the additional $\mathrm{As}_{\mathrm{i}} q(b)$ is $5.4 \mathrm{MHz}$. The point charge contribution for the nearest possible tetrahedral interstitial site is $q(p)=6.4 \mathrm{MHz}$, in total $q=11.8 \mathrm{MHz}$, which is too large compared to $q_{\text {exp }}=4.8 \mathrm{MHz}$. For the second tetrahedral interstitial site $T_{d 2}(d=4.88 \AA)$ the calculated $q$-value is only $6.0 \mathrm{MHz}$, since $q(p)$ (proportional to $1 / d^{3}$ ) amounts only to $0.6 \mathrm{MHz}$. This calculation gives a first evidence that $A s_{i}$ is located at a second nearest interstitial site.

The charge of the interstitial also influences the quadrupole interaction of the nearest ligands 1 and 2-4 (Tab. II). Estimating this also supports the $T_{d 2}$ site : on a $T_{d 1}$ interstitial site it would cause a large deviation from axial symmetry of their quadrupole tensors and a considerable deviation of their tensor $z$-axes from a [111] direction described by the angle $\theta$ in table II. This is not observed. Only the $T_{d 2}$ site of $\mathrm{As}_{\mathrm{i}}^{+}$or $\mathrm{As}_{\mathrm{i}}^{-}$at $4.88 \AA$ from $\mathrm{As}_{\mathrm{Ga}}$ would be compatible with the experiment, since a small $q^{\prime}$ of $0.7 \mathrm{MHz}$ could not be resolved within the ENDOR line width. The $q$-values estimated for ligand 1 are slightly different from ligands 2-4 and give rise to the dashed line in the ENDOR angular dependence of figure 1 . Thus only three of the four n.n. are equivalent (As 2-4).

The charged interstitial must also influence the As neighbors in the third shell. Three of the 12 nuclei see the charged $\mathrm{As}_{\mathrm{i}}$ in first neighbor distance ( $d=2.44 \AA$ ) labelled as IIIa in Fig. 3). The $\mathrm{As}_{\mathrm{i}}$ charge must cause a large quadrupole interaction on these 3 nuclei. The total $q$-value of the IIIa nuclei is calculated to be $3.0 \mathrm{MHz}$ assuming a positively charged $\mathrm{As}_{\mathrm{i}}^{+}$and $-4.5 \mathrm{MHz}$ assuming a negatively 
Table II. - Influence of the charge state and place of the As-interstitial on the quadrupole constant $q$ of the four nearest As-ligands (As 1-4) ; $q^{\prime}$ denotes the deviation from axial symmetry and the angle $\theta$ the deviation of the tensor $z$-axis from [111].

\begin{tabular}{|c|c|c|c|c|c|c|c|c|c|c|}
\hline $\begin{array}{c}\text { Site of } \mathrm{As}_{\mathrm{i}} \\
\text { with resp. } \\
\text { to } \mathrm{As}_{\mathrm{Ga}}\end{array}$ & Ligand & $q / \mathrm{MHz}$ & $\begin{array}{c}\mathrm{As}_{\mathrm{i}}^{-} \\
q^{\prime} / \mathrm{MHz}\end{array}$ & $\begin{array}{l}\text { Charg } \\
\theta / \mathrm{deg} .\end{array}$ & $\begin{array}{l}\text { states } \\
\qquad \mathrm{As}_{\mathrm{i}}^{+} \\
q / \mathrm{MHz}\end{array}$ & $q^{\prime} / \mathrm{MHz}$ & $\theta /$ deg. & $\begin{array}{l}\mathrm{As}_{\mathrm{i}}^{+++} \\
q / \mathrm{MHz}\end{array}$ & $q^{\prime} / \mathrm{MHz}$ & $\theta /$ deg. \\
\hline $\begin{array}{l}T_{d 1} \\
(2.44 \AA)\end{array}$ & $\begin{array}{l}\text { As } 1 \\
\text { As } 2-4\end{array}$ & $\begin{array}{l}12.5 \\
13.3\end{array}$ & $\begin{array}{l}0 \\
2.9\end{array}$ & $\begin{array}{r}0 \\
-4\end{array}$ & $\begin{array}{l}13.4 \\
13.2\end{array}$ & $\begin{array}{c}0 \\
-1.7\end{array}$ & $\begin{array}{l}0 \\
5\end{array}$ & $\begin{array}{l}14.2 \\
15.6\end{array}$ & $\begin{array}{r}0 \\
-4\end{array}$ & $\begin{array}{r}0 \\
17\end{array}$ \\
\hline $\begin{array}{l}T_{d 2} \\
(4.88 \AA)\end{array}$ & $\begin{array}{l}\text { As } 1 \\
\text { As 2-4 }\end{array}$ & $\begin{array}{l}12.8 \\
13.3\end{array}$ & $\begin{array}{l}0 \\
0.8\end{array}$ & $\begin{array}{r}0 \\
-1\end{array}$ & $\begin{array}{l}13.1 \\
12.8\end{array}$ & $\begin{array}{c}0 \\
-0.6\end{array}$ & $\begin{array}{l}0 \\
1\end{array}$ & $\begin{array}{l}13.4 \\
12.3\end{array}$ & $\begin{array}{l}0 \\
2.1\end{array}$ & $\begin{array}{l}0 \\
2\end{array}$ \\
\hline
\end{tabular}

Exp. value of $q$ for As $2-4$ is $|q|=11.7 \pm 0.2 \mathrm{MHz}, \theta=0, q^{\prime}=0$. The value for As 1 can be $12.2 \mathrm{MHz}$. Since the shift of its ENDOR line from those of nuclei 2-4 is due to a combined effect of $a$ and $q$, and a may also be changed slightly, $q$ cannot be determined with more accuracy.

$$
q=1 / 2 Q_{z z}, \quad q^{\prime}=1 / 2\left(Q_{z z}-Q_{y y}\right) .
$$

charged $\mathrm{As}_{\mathrm{i}}$. Although the sign of $q$ cannot be determined by the experiment, comparison shows, that good agreement is achieved for the positively charged $\mathrm{As}_{\mathrm{i}}$ (Tab. I). This follows also from the compensation behaviour of EL2. The $\mathrm{As}_{\mathrm{i}}$ influence on the $q$ of IIIb and IIIc is negligible.

\section{Correlation with energy levels.}

We now address the question, whether the $A s_{\mathrm{Ga}}-\mathrm{As}_{\mathrm{i}}$ complex can be identified with the EL2 defect. A correlation between the magnetic resonance spectra and the energy levels and optical bands can be made by performing photo-ODESR and photo-ODENDOR measurements in $p$-type GaAs : $\mathrm{Zn}$. In this material the Fermi level is at the $\mathrm{Zn}$ acceptors, the defect $+/++$ level is empty. It can be populated by exciting electrons from the valence band into it. The MCD of the now populated state is monitored as a function of excitation photon energy (Fig. 7a). Above a threshold of $E_{v}+(0.52 \pm 0.02) \mathrm{eV}$ the MCD (Fig. 7b), ODESR and ODENDOR spectra of the $\mathrm{As}_{\mathrm{Ga}}-\mathrm{As}_{\mathrm{i}}$ interstitial pair are observed. Above a second threshold $E_{v}+(0.74 \pm 0.02) \mathrm{eV}$ the signal decreases again, since now a second electron is captured to form the diamagnetic pair. With the creation of this diamagnetic defect by pumping light $(h v>0.74 \mathrm{eV})$, an absorption band at $1.2 \mathrm{eV}$ appears, which shows the typical EL2 behavior, i.e. persistent bleaching and thermal recovery at $140 \mathrm{~K}$.

The presence of an additional isolated $\mathrm{As}_{\mathrm{Ga}}$ in s.i. $\mathrm{GaAs}$ is excluded from our experiments. A possible candidate for an isolated antisite in GaAs is the defect produced by electron irradiation of $n$-type GaAs. It shows the identical central hyperfine splitting in its ESR spectrum, its MCD spectrum is, however, markedly different (Fig. 7c). Its shape, a single derivative, indicates an excited state only split by spin-orbit-interaction. It shows no metastable
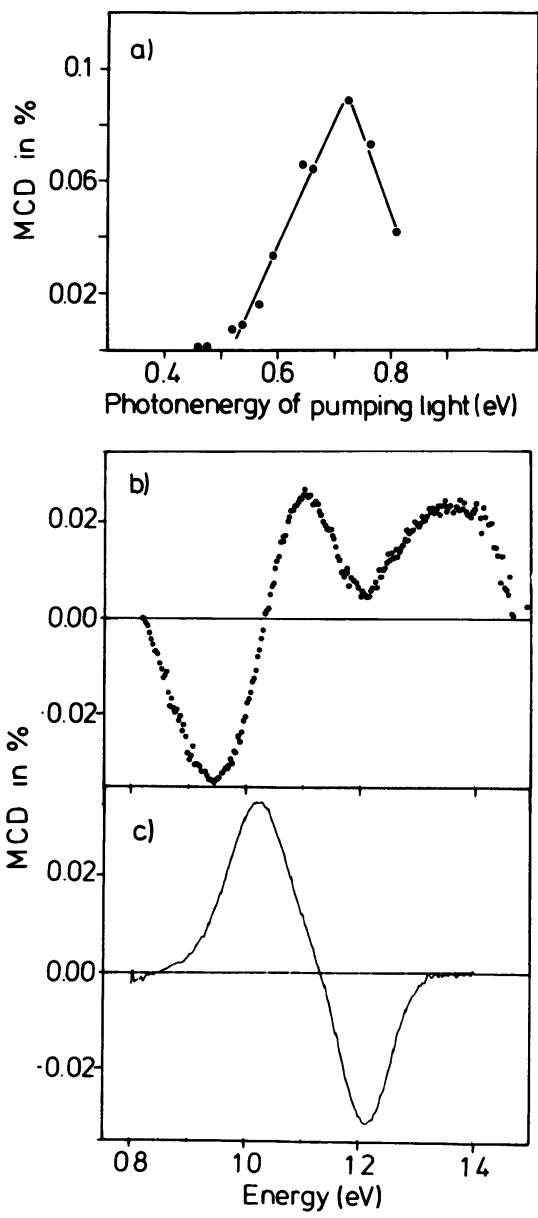

Fig. 7. - a) Excitation spectrum of the magnetic circular dichroism (MCD) of the $\mathrm{As}_{\mathrm{Ga}}-\mathrm{As}_{\mathrm{i}}$ pair in p-type GaAs: Zn. b) MCD spectrum of the photo-excited $\mathrm{As}_{\mathrm{Ga}}-\mathrm{As}_{\mathrm{i}}$ pair in p-type GaAs : Zn. c) MCD spectrum of $\mathrm{n}$ type $\mathrm{GaAs}: \mathrm{Si}$ after $2 \mathrm{MeV}$ electron irradiation (dose : $2 \times 10^{17} \mathrm{e}^{-} \mathrm{cm}^{-2}$ ).

quenching properties, its MCD and ESR spectrum is not influenced by light irradiation. In s.i. GaAs only 
one defect, the $A s_{G a}-A s_{i}$ pair, is present with its typical MCD shape in (Fig. 7b). The ODESR and ODENDOR lines of $\mathrm{As}_{\mathrm{Ga}}-\mathrm{As}_{\mathrm{i}}$ are connected only to this MCD.

\section{Conclusions.}

In s.i. material the occupation of $\mathrm{EL}^{+} /++$and $\mathrm{EL} 2^{0 /+}$ is controlled by the number of shallow acceptors compensated by EL2. The atomic model of EL2 requires a modification of the simple three level $\left(N_{\mathrm{EL} 2}>\left(N_{\text {shAcc }}-N_{\text {shD }}\right)\right) \quad$ compensation mechanism [27], since in the neutral charge state of EL2 the defect pair is positively charged $\left(\mathrm{As}_{\mathrm{Ga}}^{0}-\mathrm{As}_{\mathrm{i}}^{+}\right)$. Therefore the concentration of the shallow acceptors should be greater than EL2.

The spatially resolved measurements of the two charge states of EL2 across a 2-inch s.i. wafer shows that the total EL2 concentration is homogeneously distributed across the wafer [28]. EL2 ${ }^{0}$ shows a Wshaped profile, the EL2 ${ }^{+}$charge state is anticorrelated with a M-shaped profile. That means that the acceptors which determine the occupation of the two charge states must show a M-shaped distribution, their concentration must at least be of the order of
$2-3 \times 10^{16} \mathrm{~cm}^{-3}$ [28]. Carbon believed to be the dominant acceptor, does not satisfy this criterion. It is rather homogeneously distributed [29, 30] and semi-insulating GaAs can be grown with very low carbon content. We can conclude that the dominant acceptors are of intrinsic origin (gallium vacancies, gallium antisite defects or complexes including intrinsic acceptors). Good candidates are the new ESRcentres observed after quenching of EL2 [31, 32].

The ESR-spectrum with $g=1.95$ has a complex structure including a partly resolved hyperfine structure. Its intensity indicates concentrations $>10^{17} \mathrm{~cm}^{-3}$. If it can be verified that the observation of this defect is not caused by an electric dipole transition, its concentration exceeds the typical EL2 concentration in LEC GaAs by a factor of 2-3. The determination of the residual acceptor concentration in connection with a spatial profile measurement can act as an examination of the structure models of EL2.

\section{Acknowledgments.}

It is a pleasure to thank D. M. Hofmann for fruitful cooperation and J.-M. Spaeth for his interest and support of this work.

\section{References}

[1] Vincent, G. and BoIs, D., Solid State Commun. 27 (1978) 431.

[2] Holmes, D. E., Elliott, K. R., Chen, R. T. and KIRKPATRIK, C. G. in : Semi-Insulating III-V Materials, Eds S. Makram-Ebeid and B. Tuck 19 (Shiva, Nantwich, 1982).

[3] TsukadA, N., KIKUTA, T. and IshidA, K., Jpn J. Appl. Phys. 24 (1985) L689.

[4] KaminsKa, M., SKowronsKi, M. and KuszKo, W., Phys. Rev. Lett. 55 (1985) 2204.

[5] Lagowski, J., Gatos, H. C., Parsey, J. M., WaDA, K., KAMINSKA, M. and WALUKIEWICZ, W., Appl. Phys. Lett. 40 (1982) 342.

[6] Van Vechten, J. A., Proc. of the MRS Conf. San Francisco 46 (1985) 83.

[7] VON BARDEleben, H. J., STIEVEnARD, D. and Bourgoin, J. C., Appl. Phys. Lett. 47 (1985) 970.

[8] Weber, E. R. in Semi-Insulating III-V Materials, Eds D. C. Look and J. S. Blakemore (Shiva, Nantwich, 1984) 296.

[9] Kaufmann, U., Windscheif, J., Baeumler, M., SCHNEIDER, J. and KÖHL, F., ibid. 246.

[10] Beall, R. B., Newman, R. C. and Whitehouse, J. E., J. Phys. C : Solid State Phys. 19 (1986) 3745.

[11] Meyer, B. K. and Spaeth, J.-M., J. Phys. C : Solid State Phys. 18 (1985) L99.

[12] Wilkening, W., KaufmanN, U. and Baeumler, M., to be published.
[13] HoInkIS, M. and WEBER, E. R., private communication.

[14] Meyer, B. K., Spaeth, J.-M. and Scheffler, M., Phys. Rev. Lett. 52 (1984) 851.

[15] Hofmann, D. M., Meyer, B. K., Lohse, F. and Spaeth, J.-M., Phys. Rev. Lett. 53 (1984) 1187.

[16] NiKLAS, J. R., Radiat. Eff. 72 (1983) 39.

[17] Abragam, A. and Bleaney, B., Electron Paramagnetic Resonance of Transition Ions (Oxford, N.Y. 1970).

[18] Spaeth, J.-M., Hofmann, D. M. and Meyer, B. K., Proc. of the MRS Conf., San Francisco 46 (1985) 185.

[19] Feuchtwang, T. E., Phys. Rev. 126 (1962) 1628.

[20] Hage, J., Niklas, J. R. and Spaeth, J.-M. in Defects in Semiconductors, Eds H. J. von Bardeleben, Material Science Forum, 10-12 (1986) 259.

[21] Owen, J. and Thornley, J. H. M., Rep. Prog. Phys. 29 (1966) 675.

[22] van Engelen, P., Phys. Rev. B 22 (1980) 3144.

[23] Hage, J., Thesis, Paderborn 1987.

[24] KaufmanN, U. and SChNeider, J. in Festkörperprobleme Adv. Solid State Phys. Ed. J. Treusch (Vieweg, Braunschweig) 20 (1980) 87.

[25] Morton, J. R. and Preston, K. F., J. Magn. Reson. 30 (1978) 577.

[26] Meyer, B. K., HofmanN, D. M. and Spaeth, J.-M. in Defects in Semiconductors, Ed. von Bardeleben, Mater. Sci. Forum 10-12 (1986) 311. 
[27] Semiconductors and Semimetals, Ed. R. K. Willardson and A. C. Beer, Vol. 20 (Academic Press, 1984).

[28] Heinemann, M., Meyer, B. K., Spaeth, J.-M. and LOHNERT, K., Proc. of the International Symposium on Defect Recognition and Image Processing in III-V Compounds, Monterey USA (1987).
[29] Walukiewicz, W., Bourret, E., Yau, W. F., MCMurray, R. E., Haller, E. E. and Bliss, D., ibid.

[30] Alt, C. H., private communication.

[31] Baeumler, M., KaufManN, U. and Windscheif, J., Appl. Phys. Lett. 46 (1985) 781.

[32] Bittebierre, J., Cox, R. T. and Molva, E. in Defects in Semiconductors, Ed. H. J. von Bardeleben, Mater. Sci. Forum 10-12 (1986) 365. 